\title{
Research into Genetic Problems of Powdery Mildew Resistance Gene in Tobacco
}

\author{
Yan Chen ${ }^{1, a}$, Jiazhong Liü ${ }^{1, b}$, Hongmei $\mathrm{Li}^{1, \mathrm{C}}$ and Shuyingi $\mathrm{Li}^{1, \mathrm{~d}}$ \\ ${ }^{1}$ College of Resources and Environment, Yuxi Normal University, Yuxi 653100, China \\ achenyan305@163.coml, b14034267@qq.com, '99642367@qq.com, d576415841@qq.coml
}

\begin{abstract}
Keywords: Tobacco; Powdery Mildew; Resistance Gene; Genetic Problem
Abstract. Objective: To study the genetic problems of powdery mildew resistance gene in tobacco. Method: after tobacco powdery mildew resistant variety and susceptible variety provided by a greenhouse during May 2015 May 2016 were selected as the research object, to build a genetic model, genetic laws of resistance gene to tobacco powdery mildew were observed by adopting segregation analysis method. Results: genetics of resistance to tobacco powdery mildew was controlled by recessive genes; compatibility test showed that model E- 0 was the optimal model, i.e. genetics of resistance to powdery mildew was controlled by 2 pairs of genes, which respectively were additive-dominant-epistatic major gene and its polygene; the heritability of B1 generation major gene and polygene was $88.6 \%$ and $0.0 \%$ separately, while the one of $\mathrm{F} 2$ generation major gene was $84.5 \%$ and $0.0 \%$ respectively. Conclusion: pay attention to the selection of disease-resistant materials, interaction effect between genes and environmental factor in practice.
\end{abstract}

\section{Introduction}

In recent years, the tobacco planting range keeps expanding, but because of its single variety and change of cultivation method, tobacco disease grew accordingly, which directly affects the quality and efficiency of tobacco production. Tobacco powdery mildew belongs to a fungal disease, which was first found in Italy. Since then, it has broken out in several provinces in China, like Sichuan, Yunnan, Guangdong and Hubei and so on. It not only caused harm to tobacco leaves, but also damaged its stems and flowers, or even resulted in the whole plant dead in serious cases. Once the leaves get disease, it will affect the economic value of tobacco even if modulated. At present, the disease is mainly treated by means of prevention. However, the effect is not good, which has not only increases the cost of tobacco planting, but also caused an ecological problem. To improve the economy and efficiency of tobacco planting, it is necessary to effectively control the tobacco powdery mildew. But currently, more researches and reports have been made in wheat and cucumber powdery mildews, while researches and reports on tobacco powdery mildew are few. Therefore, this paper analyzed the genetic problem of resistance gene to tobacco powdery mildew, to promote the extension of disease-resistant variety after its genetic regularity of the resistance is to be confirmed. Now it is reported as follows.

\section{Materials and methods}

\subsection{Materials}

During May 2015 May 2016 a greenhouse provided tobacco powdery mildew resistant variety and susceptible variety, which respectively were TT7 and NC89. Seed F1 was obtained by hybridization of NC89, and seed F2 got by selfing of F1, and seeds B1 and B2 obtained by hybridization of it and TT7 and NC89 separately. Golovinomyces cichoracearum was the selected testing bacteria.

\subsection{Methods}

Sow the seeds F1, F2, B1 and B2 in the greenhouse, and implant the seeds on a nursery site after 1 month, and randomly place the seeds. When the tobacco seedling grew to 5 6 leaf stage, use spray inoculation method to implement the inoculation, and 20d later observe the incidence status. 
Construct a total of 24 genetic models, and analyze the condition of generation single plant by using segregation analysis method, at the same time clarify the value of maximum likelihood function and AIC value of each model by using IECM algorithm, and select the optimal model in combination of Akaike information criterion.

2.3 Effect judgment

Based on the classification standard of tobacco powdery mildew, class 0 means there is no scab, class 1 means the proportion of scab area in leaf area is less than 5\%, class 3 means the proportion of scab area is between $6 \% \sim 10 \%$, class 5 means the proportion of scab area $11 \% \sim 20 \%$, class 7 means the proportion of scab area $21 \% \sim 40 \%$ and class 7 means the proportion of scab area more than $41 \%$.

\section{Results}

3.1 Genetics of resistance to powdery mildew

In TT7 immune tobacco powdery mildew, both NC89 and F1 were highly susceptible. The result showed that genetics of resistance to tobacco powdery mildew was controlled by recessive gene. See Table 1.

Table 1 Comparison of disease index of tobacco powdery mildew of various generations

\begin{tabular}{cccccc}
\hline \multirow{2}{*}{ Generation } & \multicolumn{5}{c}{ Disease index } \\
\cline { 2 - 6 } & $0 \sim 20$ & $20 \sim 40$ & $40 \sim 60$ & $60 \sim 80$ & $80 \sim 100$ \\
\hline TT7 & 50 & 0 & 0 & 0 & 0 \\
NC89 & 0 & 0 & 8 & 29 & 10 \\
$\mathrm{~F}_{1}$ & 0 & 0 & 8 & 32 & 31 \\
$\mathrm{~B}_{1}$ & 52 & 15 & 20 & 82 & 89 \\
$\mathrm{~B}_{2}$ & 2 & 16 & 79 & 123 & 76 \\
$\mathrm{~F}_{2}$ & 46 & 31 & 61 & 106 & 40 \\
\hline
\end{tabular}

\subsection{Genetic model of resistance}

Based on Akaike criterion, models with a smaller AIC value were selected, which respectively were models B-1, D-0, D-2, E-0 and E- 1 . The compatibility test showed that model E-0 was the optimal one, i.e. genetics of resistance to powdery mildew was controlled by 2 pairs of genes, which respectively were additive-dominant-epistatic major gene and its polygene. See Table 2.

Table 2 Comparison of value of maximum likelihood function and AIC value of each model

\begin{tabular}{cccccc}
\hline Index & B-1 & D-0 & D-2 & E-0 & E-1 \\
\hline Value of & -4435.7 & -4536.7 & -4447.5 & -4408.5 & -4453.4 \\
maximum & & & & & \\
$\begin{array}{c}\text { likelihood } \\
\text { function }\end{array}$ & & & & & \\
AIC & 8956.8 & 8856.5 & 8965.5 & 8834.5 & 8836.7 \\
\hline
\end{tabular}

3.3 Heritability

In model E-0, additive effect of 2 pairs of main genes was basically the same, which was about -13.4, while the dominant effect was also basic similar, around 45.6. At the same time, 2 pairs of main genes showed a negative dominance. Therefore, pay attention to the selection of resistant materials and interaction effect between genes during breeding for disease resistance. 
The heritability of B1 generation major gene and polygene was $88.6 \%$ and $0.0 \%$ separately, while the one of F2 generation major gene was $84.5 \%$ and $0.0 \%$ respectively. This result showed that tobacco powdery mildew was related to the environment.

\section{Discussion}

Tobacco powdery mildew is mainly caused by golovinomyces cichoracearum, which is commonly seen in seedling stage and field stage, mostly occurring in leaf spreading to stems, flowering branches and other positions in severe cases, or even causing dead plant. Even when the disease is relatively light, due to the thin, crushing and fuzzy leaf and lack of elasticity, its economic and baking value will be greatly reduced. According to statistics, tobacco powdery mildew has a high incidence on a national scale, while the incidence range is gradually spreading, which has caused serious damage to tobacco production in China.

Domestic scholars studied the prevention and control of tobacco powdery mildew, which relies mainly on chemical method and sulfur-containing pesticide and Tuzet are adopted. The use of such kinds of agentia in large doses not only has resulted in environmental pollution problem but also has been threatening people's health.

In recent years, the research on powdery mildew has been mainly focusing on wheat, cucumber and other crops. Domestic scholars have pointed out through study that genetic laws of wheat resistance against powdery mildew was dominated by single dominant inheritance, but also accompanied by single recessive inheritance, and double dominant gene overlap inheritance. Relevant scholars[1] confirmed through study that genetic laws of cucumber resistance to powdery mildew were recessive polygene controls the heredity, single recessive gene controls the heredity and 3 pairs of genes control the heredity. At present, the report on genetics of resistance to tobacco powdery mildew is only showed in the following aspects: the heredity of Kokubu variety was controlled by repeated recessive allele, while the heredity of Pobeda3 and TB22 was controlled by single dominant gene. At the present stage, resistant germplasm to powdery mildew mainly relies on Kokubu, whose resistance is easy to transfer and hasn' t caused adverse damage to the quality of tobacco leaves, which belongs to moderate resistance. Because of its incomplete performance on shoot and most typical symptom showing in field blooming stage, blooming stage should be selected during segregation population. There is a certain difference in a small number of existing studies, and the reasons are as follows: firstly, different varieties have differentiating resistance mechanism; secondly, there may be other microspecies during preservation period of pathogen of tobacco powdery mildew affected by pathological differentiation; thirdly, genetic analysis methods and disease classification standards applied during research process are different; fourthly, powdery mildew development is related to the environment, if the test conditions are different, the research results will be affected[2].

To enrich the research on genetics of resistance to tobacco powdery mildew, with the tobacco powdery mildew resistant variety and susceptible variety provided by a greenhouse as the research object, this paper carried out the correlation research. In research, genetic segregation analysis method was used to analyze the constructed models. The research showed that genetics of resistance to tobacco powdery mildew was controlled by recessive genes, and model E- 0 was the optimal one; the heritability of B1 generation major gene and polygene was $88.6 \%$ and $0.0 \%$ separately, while the one of $\mathrm{F} 2$ generation major gene was $84.5 \%$ and $0.0 \%$ respectively. The result indicated that attention should be paid to disease-resistant materials, interaction effect and environment and other factors in practice. Relevant scholars [3] obtained experimental materials by hybridization and selfing with TT7 and Burley 21 as the research objects, and go the result that additive effect of tobacco powdery mildew was -1.45 , which was consistent with the research report.

During the compatibility test involved in research of resistance to powdery mildew, genetic regularity of the resistance to powdery mildew was clarified mainly by using chi-square test in combination of disease-resistant shape separation ratio and relevant genetic laws. This method has higher requirements of plant disease resistance grade. During research process, human intervention 
should be conducted to the plant, and divide it into different grades, such as high sensitivity, infection, moderate resistance or highly resistance and so on. In this case, subjective factors will affect the accuracy of research results. Chi-square test is more suitable for quality analysis, while polygene control belongs to quantitative analysis. Therefore, appropriate test methods should be selected when doing research. Domestic scholars adopted genetic segregation analysis method to apply it in quantitative analysis, and respectively analyzed the genetic laws of major genes and polygenes, further improving the objectivity and accuracy of analysis results [4].

At the present stage, there hasn' $t$ been an effective method for inoculation of tobacco powdery mildew. Domestic scholars analyzed the following inoculation methods with cucumber powdery mildew as the research object. The first one is anemophily inoculation method, i.e. put diseased or infected plant and inoculation materials in the same space, and then inoculate with fair wind. At this moment, exercise strict control over the temperature and humidity, which should be at around $25^{\circ} \mathrm{C}$ and $70 \%$ respectively. It has the advantage of easy operation but has the disadvantage of lack of uniformity. The second one is oscillating method with the most prominent feature of simple and convenient use, i.e. use a sprayer to wet the material leaf, and put infected leaves above test materials, flick them, after this pay attention to the adjustment of temperature and humidity. This method has the disadvantage of lack of precision; the third one is spray inoculation method, i.e. prepare beaker, adjust suspension concentration and spray it evenly on experimental materials. In this paper, the third method was selected, to ensure both the evenness and accuracy [5].

In conclusion, tobacco powdery mildew belongs to a fungal disease. The existing researches mostly focus on symptom and prevention and treatment of tobacco powdery mildew, but never paying attention to its molecular biology study. To avoid the powdery mildew from arising, this paper made clear the genetic laws of resistance genes of tobacco powdery mildew by genetic segregation analysis, to ensure the effectiveness of breeding work of tobacco powdery mildew.

\section{References}

[1] Liu Yanhua, Ren Min, Wang Zhide et al. Genetic Analysis of Resistance Gene of Tobacco Powdery Mildew [N]. Journal of Plant Genetic Resources, 2013, 23 (07): 668-672.

[2] Mou Jianying, Qian Yumei, Ren Min et al. QTL Mapping of Powdery Mildew Resistance Genes in Tobacco [N]. Journal of Chinese Tobacco, 2013, 18 (04): 105-108.

[3] Mou Jianying. A Study of Genetic Analysis of Resistance to Powdery Mildew in Tobacco Varieties [D]. Beijing: Chinese Academy of Agricultural Sciences, 2013:14-16.

[4] Lei Xiuyu. Evaluation on the Practicability of Molecular Markers of Powdery Mildew Resistance Genes in Wheat [D]. Hebei: Hebei Normal University of Science and Technology, 2013:10-15.

[5] Fu Haining. Pea Phenotype and Genotype Identification of Resistance to Powdery Mildew in Pea [D]. Gansu: Gansu Agricultural University , 2014: 12-14. 